\title{
Transcatheter closure of atrial septal communication: Impact on quality of life in mid-term follow-up
}

\author{
Maria Lelakowska ${ }^{1, A-D}$, Paweł Tomasz Matusik', ${ }^{2,-E}$, Piotr Stanisław Podolec ${ }^{3, F}$, Maria Olszowska ${ }^{3, E}$, \\ Jadwiga Maria Nessler, ${ }^{1, E}$, Natalia Podolec ${ }^{4, B}$, Tadeusz Przewłocki ${ }^{3, B}$, Monika Komar ${ }^{3, A, B}$ \\ ${ }^{1}$ Department of Coronary Disease and Heart Failure, John Paul II Hospital, Kraków, Poland \\ 2 Department of Electrocardiology, Institute of Cardiology, Jagiellonian University Medical College, John Paul II Hospital, Kraków, Poland \\ ${ }^{3}$ Department of Cardiac and Vascular Diseases, Institute of Cardiology, Jagiellonian University Medical College, John Paul II Hospital, Kraków, Poland \\ ${ }^{4}$ Faculty of Medicine, Jagiellonian University Medical College, Kraków, Poland
}

A - research concept and design; B - collection and/or assembly of data; $\mathrm{C}$ - data analysis and interpretation;

$D$ - writing the article; $E$ - critical revision of the article; $F$ - final approval of the article

\section{Address for correspondence}

Monika Komar

E-mail:monniik@interia.pl

Funding sources

None declared

Conflict of interest

None declared

Received on July 26, 2018

Reviewed on November 25, 2018

Accepted on December 30, 2018

Published online on June 18, 2019

Cite as

Lelakowska M, Matusik PT, Podolec PS, et al. Transcatheter closure of atrial septal communication: Impact on quality of life in mid-term follow-up. Adv Clin Exp Med. 2019;28(8):1079-1085. doi:10.17219/acem/102440

DOI

10.17219/acem/102440

\section{Copyright}

Copyright by Author(s)

This is an article distributed under the terms of the

Creative Commons Attribution Non-Commercial License

(http://creativecommons.org/licenses/by-nc-nd/4.0/)

\begin{abstract}
Background. Atrial septal defect (ASD) and patent foramen ovale (PFO) are specific types of atrial septal communications (ASC).

Objectives. We aimed to assess quality of life (QoL) in patients before and after percutaneous closure of ASC and determine the factors influencing $\mathrm{QoL}$ in this group of patients.

Material and methods. We performed a clinical assessment and conducted an SF-36 questionnaire, electrocardiography and echocardiography studies in patients before and 6 months after percutaneous ASC closure.

Results. Patients with ASD ( $n=56$ ) had a lower SF-36 total score than those with PFO $(n=73)$, before and after percutaneous ASC occlusion (both $p<0.001)$. After the procedure, the improvement of SF-36 total score in patients with ASD or atrial fibrillation was greater ( $p<0.001$ and $p=0.005$, respectively). We observed correlations between improvement of $\mathrm{QO} \mathrm{L}$ and baseline supraventricular extrasystolic beats $\left(r_{s}=0.28 ; p=0.002\right)$, but not ventricular extrasystolic beats $\left(r_{s}=0.03 ; p=0.76\right)$. Quality of life improvement was predicted in patients with ASD by higher baseline tricuspid annular plane systolic excursion (TAPSE) and right ventricular longitudinal dimension $R^{2}=0.38 ; p<0.001$. However, in patients with PFO, this was predicted by TAPSE, lack of arterial hypertension and usage of angiotensin-converting enzyme inhibitors, $R^{2}=0.30 ; p<0.001$.

Conclusions. Patients with ASD have lower QoL than those with PFO before and after percutaneous ASC occlusion. Six months after the procedure, the improvement of QoL in patients with ASD was higher than in those with PFO. The change in QoL self-assessed by patients after the procedure was associated with episodes of arrhythmia and was predicted with echocardiographic and clinical parameters.
\end{abstract}

Key words: quality of life, patent foramen ovale, atrial septal defect, transcatheter closure 


\section{Introduction}

Atrial septal communications (ASC) include ostium secundum atrial septal defect (ASD) and patent foramen ovale (PFO). The ASD is one of the most common congenital heart defects, while PFO is an anatomical variant. Those with ASD and PFO are considered as 2 different patient populations. The PFO is the most prevalent ASC and is diagnosed in about $26 \%(17-35 \%)$ of the population. A right-to-left shunt through PFO usually occurs during a temporary or permanent increase in right atrial pressure. On the other hand, PFO with concomitant valvular regurgitation and/or stenosis may be associated with leftto-right shunt. The PFO may lead to paradoxical embolism, usually in circulation related to the central nervous system. ${ }^{1-3}$ The ASD comprises about $10 \%$ of all congenital heart defects diagnosed after birth. ${ }^{4-8}$ According to European Society of Cardiology guidelines, ASD with a hemodynamically significant shunt (signs of right ventricular volume overload) and pulmonary vascular resistance $<5$ Wood units should be closed. Moreover, closure of ASD and PFO should be considered in cases of previous paradoxical systemic embolism. . $^{1,4}$

The importance of a quality of life (QoL) assessment in patients undergoing various types of medical interventions became apparent in the 1970s. With the advancement of medicine, therapeutic goals are not only set to remove the disease, which in many cases is not possible, but also to improve patient's functioning in society, fulfillment of social roles and restoration of well-being. ${ }^{9-12}$

The aim of the study was to assess QoL in patients before and after percutaneous closure of ASC (ASD and PFO) and to determine the factors influencing QoL in this group of patients.

\section{Material and methods}

\section{Patients}

The methodology of the study has been previously described in detail. ${ }^{13}$ Briefly, we included consecutive patients with ASD or PFO.

Inclusion criteria:

1) Presence of ASD or PFO planned for percutaneous closure.

2) Consent to undergo transthoracic echocardiography (TTE), transesophageal echocardiography (TEE), 24-hour Holter electrocardiogram (ECG) monitoring and percutaneous ASC closure, and to perform a clinical assessment including the SF-36 questionnaire, before and 6 months after the procedure.

Exclusion criteria:

1) Chronic atrial fibrillation (AF).

2) Patients after cardiac surgery, AF ablation or cardiovascular implantable electronic device placement.
3) The presence of significant valvular heart disease and/or other congenital cardiovascular defects and/or cardiomyopathy.

4) Left ventricular ejection fraction (LVEF) below 50\% or dementia.

5) The presence of a significant leak around the implanted septal occluder.

6) Sub-optimal imaging on echocardiography and poorly visible P-waves in ECG (non-echogenicity and poor ECG recording quality).

7) Incomplete SF-36 questionnaire.

We excluded patients with chronic AF and poorly visible P-waves because P-wave dispersion analysis was performed as a part of our study. ${ }^{13}$ From our study, we excluded 3 patients with chronic AF, 1 patient who did not complete the SF-36 questionnaire and 3 patients who did not return it. Furthermore, 1 patient was excluded due to a significant leak around the implanted occluder.

Clinical history assessment and physical examination (including assessment of cardiovascular complaints and comorbidities) were performed before percutaneous closure of the ASD and PFO and 6 months after the procedure.

\section{TTE, TEE and 24-hour Holter ECG monitoring}

Transthoracic and transesophageal echocardiography studies were performed according to recommendations from international guidelines. ${ }^{13-19}$ using the Toshiba Power Vision system (Toshiba, Tokyo, Japan) and an ultrasound probe with a frequency from $2.5 \mathrm{MHz}$ to $3.5 \mathrm{MHz}$. M-mode imaging, 2-dimensional (2D) imaging, pulse-wave Doppler, continuous wave Doppler, and color flow Doppler imaging were used. Two-dimensional imaging was used to assess the location and size of the ASC from standard views: parasternal cross-sectional view at the level of large vessels, apical 4-chamber, apical 5-chamber, and subcostal views. The morphology of the atrial septum was assessed during TEE in the bicaval view and high longitudinal view. ${ }^{16,17}$ Basic parameters of cardiac chamber quantification and valvular functions were assessed. Moreover, right ventricular pressure and pulmonary to systemic blood flow ratio (Qp/Qs) were calculated. Assessment of the Holter ECG monitoring results was performed as previously described. ${ }^{13}$

\section{Quality of life assessment}

Assessment of QoL was based on a self-assessment of patients using a 36-item SF-36 questionnaire. The SF-36 questionnaire used in our study was composed of 11 points including 36 questions, which consisted of 8 subscales for the assessment of: SF1 - physical functioning (PF); SF2 - limitations due to physical health, role-physical (RP); SF3 - social functioning (SF); SF4 - bodily pain (BP); SF5 - mental health (MH); SF6 - role limitations due to emotional problems, role-emotional (RE); SF7 - vitality (VT); 
SF8 - general health $(\mathrm{GH})$. In the final assessment, QoL index was calculated (SF-36 total score). In the interpretation of results, higher scores in the self-assessment of patients indicated better QoL. ${ }^{9-12}$

Written consent was given by all patients to perform studies and procedures according to Polish/European Society of Cardiology (ESC) standards and to perform the QoL assessment. Approval for the study was provided by the Bioethics Committee of the Jagiellonian University Medical College.

\section{Statistical analysis}

Quantitative variables were described with the mean \pm standard deviation (SD) and/or median and/or range and/or interquartile range (IQR). Qualitative variables were presented as number and/or frequency. Hypotheses about the normal distribution of the quantitative variables analyzed were verified using the Shapiro-Wilk test. Differences in quantitative variables between the 2 groups were tested with independent samples using the Student t-test or Mann-Whitney U test. An assessment of differences between qualitative variables was performed using the $X^{2}$ test or Fisher's exact test. An analysis of changes in quantitative variables, before and after procedure, was performed using the Wilcoxon matched-pairs test, while qualitative (dichotomous) variables were analyzed with McNemar's test for repeated measures. Relations between SF-36 total score and its change and other variables were tested using Spearman's rank test $\left(\mathrm{r}_{\mathrm{s}}\right)$. Selected variables associated with a change in SF-36 total score $(\mathrm{p}<0.05)$ in univariate statistical analysis, which did not substantially correlate (including correlation coefficient $\geq 0.6$ ) with other independent variables, were included into a multiple linear regression analysis. The selection of variables which significantly influenced the dependent variable, was performed using stepwise backward regression. $\mathrm{R}^{2}$ was calculated and an assessment of model adequacy using the $\mathrm{F}_{\mathrm{k}, \mathrm{n}-\mathrm{k}-1}$ test was performed, where " $k$ " is the number of variables in a model and " $n$ " is the number of patients in a group. Statistical analyses were performed with STATISTICA v. 12 software (StatSoft, Tulsa, USA).

\section{Results}

\section{Baseline patient characteristics}

The study group included 129 patients (70 female), with a mean age of $44.5 \pm 13.4$ (19-76) years, scheduled for percutaneous closure of ASD $(n=56)$ or PFO $(n=73)$. Patients undergoing percutaneous closure of ASD were older and were predominantly female when compared to those undergoing closure of PFO (Table 1). There were 10 patients with PFO and a history of stroke, while there was no history of stroke in patients with ASD. None of the patients included in the study had significant neurological deficits. When compared to patients with PFO, those with ASD more commonly suffered from episodes of palpitations (37.5\% vs $10.9 \%)$, dyspnea (32.1\% vs $9.6 \%$ ), arterial hypertension (30.4\% vs $4.1 \%)$, and pulmonary hypertension $(33.9 \%$ vs $0 \%)$ before the procedure $(\mathrm{p}<0.001$ for all comparisons between the 2 groups, Table 1). These ASD patients also more often used calcium channel blockers (CCB), $\beta$-blockers and angiotensin-converting enzyme inhibitors (ACE-I) when compared with the remainder of the patients in the study group. On the other hand, patients with PFO, when compared with ASD patients, more commonly experienced migraine episodes (Table 1). Ventricular extrasystolic and supraventricular extrasystolic beats were more prevalent in the ASD patients when compared to the remainder of patients (median (IQR): 2 (1-900 vs $1(0-3)$ ventricular extrasystolic beats/day, $\mathrm{p}=0.017$ and $178(42-540)$ vs $8(0-200)$ supraventricular extrasystolic beats/day, $\mathrm{p}<0.001)$. Detailed characteristics of the study group are shown in Table 1.

\section{Baseline QoL assessment}

There were differences in almost all the SF-36 scores between patients with ASD and PFO (Table 1). In both groups of patients with ASC, age negatively correlated with SF-36 total score (Table 2). Moreover, SF-36 total score correlated inversely with New York Heart Association (NYHA) class and positively with LVEF in patients with ASD (Table 2). We observed correlations between SF-36 total score after PFO closure and radiation absorbed dose $\left(\mathrm{r}_{\mathrm{s}}=0.31 ; \mathrm{p}=0.009\right)$ and right ventricular longitudinal dimension $\left(r_{s}=0.25 ; p=0.041\right)$. Additionally, a correlation was seen between SF-36 total score after ASD closure and mid-cavity right ventricular linear dimension $\left(r_{s}=0.29\right.$; $\mathrm{p}=0.034)$. These correlations, however, were not seen in the other groups studied or before the procedure. Left ventricular diastolic dimension, left ventricular systolic dimension, proximal right ventricular outflow tract (RVOT prox), and basal right ventricular linear dimension did not correlate with SF-36 total score before or after ASC closure in patients with ASD or PFO considered separately. Quality of life, reflected by SF-36 total score, in patients with ASD was lower than in patients with PFO (Table 1). Patients with history of stroke had a tendency towards lower SF-36 total score than the remaining subjects $(95.0$ (87-108) vs 120 (88-132); $\mathrm{p}=0.057)$.

\section{Procedures performed}

The septal occluders were successfully implanted in 124 patients. In 5 patients, the procedure was not performed (Table 1). The diameter of the implanted septal occluders ranged from $7 \mathrm{~mm}$ to $34 \mathrm{~mm}$ (median: 25; 25-28 mm). The ASC occlusion, as reflected by fluoroscopy time and radiation absorbed dose, appeared more 
Table 1. Clinical characteristics of patients undergoing closure of atrial septal communication

\begin{tabular}{|c|c|c|c|}
\hline Variable & $\begin{array}{c}\text { ASD } \\
(n=56)\end{array}$ & $\begin{array}{c}\text { PFO } \\
(n=73)\end{array}$ & $\mathrm{p}$-value \\
\hline Age, mean $\pm S D$ [years] & $49.8 \pm 13.3$ & $40.5 \pm 12.0$ & $<0.001$ \\
\hline Male sex, n (\%) & $12(21.4)$ & $47(64.4)$ & $<0.001$ \\
\hline \multicolumn{4}{|c|}{ Comorbidities and CVD risk factors, n (\%) } \\
\hline $\begin{array}{l}\text { Arterial hypertension } \\
\text { Pulmonary hypertension } \\
\text { Hyperlipidemia } \\
\text { Diabetes mellitus } \\
\text { Obesity } \\
\text { Smoking } \\
\text { Anemia } \\
\text { Migraine } \\
\text { Vasovagal syndrome } \\
\text { Stroke/TIA } \\
\text { Atrial fibrillation }\end{array}$ & $\begin{array}{c}17(30.4) \\
19(33.9) \\
15(26.8) \\
4(7.1) \\
3(5.4) \\
14(25.0) \\
0(0.0) \\
0(0.0) \\
1(1.8) \\
4(7.1) \\
17(30.4)\end{array}$ & $\begin{array}{c}3(4.1) \\
0(0.0) \\
7(9.6) \\
1(1.4) \\
2(2.7) \\
9(12.3) \\
1(1.4) \\
11(15.1) \\
3(4.1) \\
24(32.9) \\
8(11.0)\end{array}$ & $\begin{array}{c}<0.001 \\
<0.001 \\
0.010 \\
0.166 \\
0.652 \\
0.062 \\
0.999 \\
0.002 \\
0.632 \\
<0.001 \\
0.006\end{array}$ \\
\hline \multicolumn{4}{|c|}{ Quality of life assessed using SF-36 questionnaire, at baseline } \\
\hline $\begin{array}{l}\text { SF-36 total score } \\
\text { Physical functioning } \\
\text { Limitations due to physical health } \\
\text { Social functioning } \\
\text { Bodily pain } \\
\text { Mental health } \\
\text { Role limitations due to emotional problems } \\
\text { Vitality } \\
\text { General health }\end{array}$ & $\begin{array}{c}99(68-129) \\
41(29-46) \\
5(0-10) \\
5(4-7) \\
6(4-9) \\
15(11-18) \\
5(0-15) \\
11(9-16) \\
11(9-15)\end{array}$ & $\begin{array}{c}124(96-132) \\
44(41-48) \\
10(5-20) \\
6(5-8) \\
8(6-9) \\
17(11-19) \\
15(5-15) \\
13(8-17) \\
12(10-15)\end{array}$ & $\begin{array}{c}<0.001 \\
0.001 \\
<0.001 \\
0.005 \\
0.084 \\
0.348 \\
0.006 \\
0.159 \\
0.079\end{array}$ \\
\hline \multicolumn{4}{|c|}{ Echocardiographic parameters, n (\%) } \\
\hline $\begin{array}{l}\text { Left-to-right shunt } \\
\text { Interatrial septal aneurysm } \\
\text { Enlarged LA } \\
\text { Enlarged RA } \\
\text { Enlarged right ventricle } \\
\text { Myocardial hypertrophy }\end{array}$ & $\begin{array}{l}54(96.4) \\
11(19.6) \\
35(62.5) \\
37(66.1) \\
33(58.9) \\
9(16.1)\end{array}$ & $\begin{array}{l}41(56.2) \\
50(68.5) \\
14(19.2) \\
14(19.2) \\
16(21.9) \\
4(5.5)\end{array}$ & $\begin{array}{c}<0.001 \\
<0.001 \\
<0.001 \\
<0.001 \\
<0.001 \\
0.074\end{array}$ \\
\hline \multicolumn{4}{|c|}{ Device, n (\%) } \\
\hline $\begin{array}{l}\text { Cardia Ultrasept ASD occluder } \\
\text { Cardia Ultrasept PFO occluder } \\
\text { Memopart ASD occluder } \\
\text { No implanted device }\end{array}$ & $\begin{aligned} & 4(7.1) \\
0 & (0.0) \\
51 & (91.1) \\
1 & (1.8)\end{aligned}$ & $\begin{array}{c}0(0.0) \\
69(94.5) \\
0(0.0) \\
4(5.5)\end{array}$ & - \\
\hline \multicolumn{4}{|c|}{ Procedure, n (\%) } \\
\hline $\begin{array}{l}\text { Without complications } \\
\text { Stopped due to complications } \\
\text { Unsuccessful }\end{array}$ & $\begin{array}{c}55(98.2) \\
0(0.0) \\
1(1.8)\end{array}$ & $\begin{aligned} 69 & (94.5) \\
1 & (1.4) \\
3 & (4.1)\end{aligned}$ & NS \\
\hline \multicolumn{4}{|c|}{ Medications, n (\%) } \\
\hline $\begin{array}{l}\text { CCB } \\
\text { Beta-blocker } \\
\text { ACE-I }\end{array}$ & $\begin{array}{l}18(32.1) \\
17(30.4) \\
17(30.4)\end{array}$ & $\begin{aligned} 1 & (1.4) \\
10 & (13.7) \\
5 & (6.8)\end{aligned}$ & $\begin{array}{c}<0.001 \\
0.021 \\
<0.001\end{array}$ \\
\hline
\end{tabular}

ACE-I - angiotensin-converting enzyme inhibitor; ASD - atrial septal defect; CCB - calcium channel blocker; CVD - cardiovascular disease; LA - left atrium; N - number; NS - nonsignificant; PFO - patent foramen ovale; RA - right atrium; SD - standard deviation; SF-36 - 36-item SF-36 questionnaire; TIA - transient ischemic attack. Values are presented as mean \pm SD or median (interquartile range) or number and percentage.

difficult in patients with ASD when compared to patients with PFO (fluoroscopy time: $7.4(4-15)$ vs 4 (3-6) min, $\mathrm{p}<0.001$; radiation absorbed dose: $29(18-113)$ vs $16(10-$ 36) mGy, p < 0.001). In 1 (0.8\%) case, a transient rhythm disorder was observed. There were no serious complications, no fractures of the device and no device embolizations. All patients remained well with no complications or new symptoms at the 6-month follow-up.

\section{Patient characteristics and quality of life after ASC closure}

Six months after the procedure, reduction of episodic palpitations, dyspnea and $\mathrm{AF}$, as well as an increase in NYHA class were observed, and in these terms ASD patients did not significantly differ from patients with PFO.

In addition, 6 months after the procedure, higher SF-36 total scores were noted in patients with ASD and PFO (Table 3). There were differences in almost all the SF-36 scores between patients with ASD and PFO, except for the SF, BP, MH, and vitality subscales (Table 4). In patients with ASD, significant improvement in the QoL parameters were noted, with the exception of the BP subscale $(\mathrm{p}=0.675)$. On the other hand, in patients with $\mathrm{PFO}$ after the procedure, a significant improvement in SF-36 QoL parameters was observed, except for the SF ( $\mathrm{p}=0.253)$ and BP subscales $(p=0.166)$. After percutaneous ASC occlusion, the mean improvement in QoL was higher in patients with ASD when compared to patients with PFO (Table 3). Increased change in SF-36 total score was associated with presence of arterial hypertension ( $p=0.013)$, episodes of dyspnea $(\mathrm{p}=0.034)$, palpitations $(\mathrm{p}=0.048)$, and use of CCB ( $p=0.001), \beta$-blockers $(p=0.040)$ and ACE-I ( $p=0.003)$, presence of interatrial septal aneurysm ( $p=0.016)$, and myocardial hypertrophy $(\mathrm{p}=0.018)$ before the procedure. Importantly, patients with AF had a higher improvement in SF-36 total score (14 (7-22) vs 6 (1-16); $\mathrm{p}=0.005)$. Those with AF episode reduction, when compared to the remainder, were also characterized by a higher change in SF-36 total score (16 (7-320 vs 7 (1-18); p = 0.03). We also observed correlations between an increase in change of the SF-36 total score (difference between 6 months after ASC occlusion and baseline) and baseline supraventricular extrasystolic beats (SVEB; $\left.r_{s}=0.28 ; p=0.002\right)$. However, correlations were not observed between increase in the change of SF-36 total score and ventricular extrasystolic beats (VEB; $\left.r_{s}=0.03 ; p=0.76\right)$. Patients with ASD had a higher improvement in SF-36 total score (14 (6-26) vs $5(1-13)$; $\mathrm{p}=0.003)$. Importantly, increase in the change of SF-36 total score correlated with baseline RVOT prox $\left(r_{s}=0.20 ; p=0.03\right)$, basal right ventricular linear dimension (RVD1) $\left(r_{s}=0.31\right.$; $\mathrm{p}<0.001$ ), mid-cavity right ventricular linear dimension 
Table 2. Spearman's correlations $\left(r_{s}\right)$ between quantitative variables and SF-36 total score at baseline and after closure of atrial septal communication

\begin{tabular}{|c|c|c|c|c|c|c|}
\hline \multirow[t]{2}{*}{ Variable } & \multicolumn{3}{|c|}{$\begin{array}{l}\text { SF-36 total score before ASC closure } \\
\qquad r_{s} \text { (p-value) }\end{array}$} & \multicolumn{3}{|c|}{$\begin{array}{l}\text { SF-36 total score after ASC closure } \\
\qquad r_{s} \text { (p-value) }\end{array}$} \\
\hline & ASC & ASD & PFO & ASC & ASD & PFO \\
\hline Age [years] & $-0.34(<0.001)$ & $-0.28(0.038)$ & $-0.32(0.005)$ & $-0.32(<0.001)$ & $-0.34(0.010)$ & $-0.28(0.022)$ \\
\hline NYHA class & $-0.31(<0.001)$ & $-0.29(0.030)$ & $-0.19(0.113)$ & $-0.32(<0.001)$ & $-0.37(0.006)$ & $-0.13(0.302)$ \\
\hline \multicolumn{7}{|c|}{ Echocardiography } \\
\hline LVEF [\%] & $0.22(0.014)$ & $0.59(<0.001)$ & $-0.01(0.944)$ & $0.37(<0.001)$ & $0.71(<0.001)$ & $0.21(0.090)$ \\
\hline TAPSE [mm] & $-0.29(0.001)$ & $-0.38(0.004)$ & $-0.10(0.342)$ & $-0.04(0.662)$ & $-0.18(0.189)$ & $0.21(0.077)$ \\
\hline LA area $\left[\mathrm{cm}^{2}\right]$ & $-0.20(0.025)$ & $-0.29(0.029)$ & $0.09(0.426)$ & $-0.13(0.165)$ & $-0.26(0.053)$ & $0.17(0.168)$ \\
\hline RA area $\left[\mathrm{cm}^{2}\right]$ & $-0.21(0.016)$ & $-0.29(0.030)$ & $0.04(0.752)$ & $-0.10(0.257)$ & $-0.19(0.173)$ & $0.13(0.296)$ \\
\hline Qp/Qs ratio & $-0.33(<0.001)$ & $-0.23(0.094)$ & * & $-0.34(<0.001)$ & $-0.19(0.161)$ & * \\
\hline \multicolumn{7}{|c|}{ Procedure } \\
\hline Fluoroscopy time [min] & $-0.31(<0.001)$ & $-0.31(0.022)$ & $-0.04(0.711)$ & $-0.30(0.001)$ & $-0.35(0.009)$ & $0.10(0.402)$ \\
\hline
\end{tabular}

ASD - atrial septal defect; ASC - atrial septal communication; LVEF - left ventricular ejection fraction; NYHA - New York Heart Association; PFO - patent foramen ovale; RA - right atrium; TAPSE - tricuspid annular plane systolic excursion; LA - left atrium; Qp/Qs ratio - pulmonary to systemic blood flow ratio; SF-36 - 36-item SF-36 questionnaire. *Qp/Qs ratio = 1 in all patients.

Table 3. Changes in SF-36 total score before and 6 months after successful closure of atrial septal communication

\begin{tabular}{|c|c|c|c|c|c|c|}
\hline \multirow[b]{2}{*}{ Variable } & \multicolumn{6}{|c|}{ SF-36 total score } \\
\hline & $\begin{array}{c}\text { ASC } \\
\text { before } \\
(n=124)\end{array}$ & $\begin{array}{c}\text { ASC } \\
6-\mathrm{m} \mathrm{FU}\end{array}$ & $\begin{array}{c}\text { ASD } \\
\text { before } \\
(n=55)\end{array}$ & $\begin{array}{c}\text { ASD } \\
6-\mathrm{m} \mathrm{FU}\end{array}$ & $\begin{array}{c}\text { PFO } \\
\text { before } \\
(n=69)\end{array}$ & $\begin{array}{c}\text { PFO } \\
6-\mathrm{m} \mathrm{FU}\end{array}$ \\
\hline Median & 111 & 121 & 98 & 117 & 120 & 131 \\
\hline Interquartile range & $87.5-131.0$ & $102.5-139.0$ & $56-129$ & $82-136$ & $96-132$ & $121-140$ \\
\hline$p$-value & \multicolumn{2}{|c|}{$<0.001^{*}$} & \multicolumn{2}{|c|}{$<0.001^{*}$} & \multicolumn{2}{|c|}{$<0.001^{*}$} \\
\hline
\end{tabular}

6-m FU - 6-month follow-up; ASD - atrial septal defect; ASC - atrial septal communication; PFO - patent foramen ovale; SF-36 - 36-item

SF-36 questionnaire. Values are presented as median (interquartile range). ${ }^{*}$ p-value for comparison of patients before and after the procedure.

(RVD2) ( $\left.\mathrm{r}_{\mathrm{s}}=0.35 ; \mathrm{p}<0.001\right)$, longitudinal right ventricular dimension (RVD3) $\left(\mathrm{r}_{\mathrm{s}}=0.38 ; \mathrm{p}<0.001\right)$, and TAPSE $\left(r_{s}=0.42 ; p<0.001\right)$, but not LVEF $\left(r_{s}=-0.005 ; p=0.95\right)$. Additionally, correlations between increase in the change of SF-36 total score and baseline left and right atrial area

Table 4. Comparison of quality of life assessed with SF-36 between patients after atrial septal communication occlusion (ASD, PFO)

\begin{tabular}{|l|c|c|c|}
\hline \multicolumn{1}{|c|}{ Variable } & \multicolumn{1}{|c|}{$\begin{array}{c}\text { ASD }^{*} \\
(\mathrm{n}=55)\end{array}$} & $\begin{array}{c}\text { PFO* } \\
(\mathrm{n}=69)\end{array}$ & p-value \\
\hline $\begin{array}{l}\text { SF-36 total score } \\
117(82-136)\end{array}$ & $131(121-140)$ & $<0.001$ \\
\hline $\begin{array}{l}\text { Physical functioning } \\
\text { Limitations due } \\
\text { to physical health }\end{array}$ & $10(31-44)$ & $48(44-48)$ & $<0.001$ \\
\hline $\begin{array}{l}\text { Social functioning } \\
\text { Bodily pain }\end{array}$ & $6(5-8)$ & $6(5-8)$ & 0.844 \\
\hline $\begin{array}{l}\text { Mental health } \\
\text { Role limitations due }\end{array}$ & $17(12-21)$ & $17(12-21)$ & 0.957 \\
\hline to emotional problems & $15(5-15)$ & $15(15-15)$ & 0.009 \\
\hline $\begin{array}{l}\text { Vitality } \\
\text { General health }\end{array}$ & $13(9-16)$ & $16(9-17)$ & 0.092 \\
\hline
\end{tabular}

ASD - atrial septal defect; PFO - patent foramen ovale; SF-36 - a 36-item SF-36 questionnaire. Values are presented as median (interquartile range). * In 5 patients the procedure was not performed (in 4 patients with PFO and in 1 patient with ASD). were observed $\left(r_{s}=0.21 ; p=0.02\right.$ and $r_{s}=0.30 ; p<0.001$, respectively). We also observed correlations between increase in the change of SF-36 total score and decrease in SVEB $\left(r_{s}=0.19 ; p=0.04\right)$, but not VEB $\left(r_{s}=-0.05 ; p=0.55\right)$.

Change in SF-36 total score in patients with ASD was predicted by TAPSE and RVD3, while in patients with PFO this was predicted by TAPSE, lack of arterial hypertension and ACE-I use (Table 5).

\section{Discussion}

In patients with $\mathrm{ASD}$, the most commonly reported symptoms are exertional dyspnea, limitation of physical condition and paroxysmal palpitations. Among the causes of gradual deterioration of clinical status of patients with ASD are age-dependent decline in left ventricular diastolic compliance, which increases left-to-right shunt, the development of pulmonary hypertension, and the appearance of AF (30.4\% of our patients with ASD), which often initiates right ventricular heart failure. ${ }^{3}$ On the other hand, the presence of PFO is associated with an increased risk of crossed (paradoxical) embolism, which may cause a cryptogenic stroke. ${ }^{1,2}$ In our study, stroke/TIA occurred in $32.9 \%$ of patients with PFO. 
Table 5. Multiple regression analysis of predictors of change in SF-36 total score (difference between 6 months after atrial septal communication occlusion and baseline), which reflects general increase in SF-36 total score

\begin{tabular}{|c|c|c|c|c|c|c|}
\hline \multirow{2}{*}{$\begin{array}{c}\text { Multiple regression } \\
\text { analysis }\end{array}$} & \multirow{2}{*}{ Variables } & \multirow{2}{*}{$\begin{array}{l}\text { Standardized } \\
\text { coefficients } \beta\end{array}$} & \multirow{2}{*}{$\begin{array}{l}\text { Unstandardized } \\
\text { coefficients B }\end{array}$} & \multicolumn{2}{|c|}{$95 \% \mathrm{Cl}$ for $\mathrm{B}$} & \multirow{2}{*}{$p$-value } \\
\hline & & & & lower & upper & \\
\hline \multirow{4}{*}{$\begin{array}{l}\operatorname{ASC}\left(R^{2}=0.35\right. \\
\left.F_{4,119}=15.99 ; p<0.001\right)\end{array}$} & TAPSE $[\mathrm{mm}]$ & 0.40 & 3.14 & 1.93 & 4.35 & $<0.001$ \\
\hline & RVD3 [mm] & 0.26 & 0.63 & 0.26 & 1.00 & 0.001 \\
\hline & arterial hypertension & -0.38 & -10.18 & -20.00 & -0.38 & 0.042 \\
\hline & ACE-I & 0.42 & 10.54 & 1.28 & 19.79 & 0.026 \\
\hline \multirow{2}{*}{$\begin{array}{l}\text { ASD }\left(R^{2}=0.38 ;\right. \\
F=2,52=15.8 ; p<0.001)\end{array}$} & TAPSE $[\mathrm{mm}]$ & 0.38 & 2.76 & 1.04 & 4.48 & 0.002 \\
\hline & RVD3 [mm] & 0.36 & 1.05 & 0.37 & 1.73 & 0.003 \\
\hline \multirow{3}{*}{$\begin{array}{l}\mathrm{PFO}\left(R^{2}=0.30\right. \\
\left.F_{3,65}=9.48 ; p<0.001\right)\end{array}$} & TAPSE $[\mathrm{mm}]$ & 0.38 & 3.41 & 1.51 & 5.30 & 0.001 \\
\hline & arterial hypertension & -0.34 & -16.38 & -28.12 & -3.64 & 0.013 \\
\hline & ACE-I & 0.44 & 13.90 & 5.59 & 22.2 & 0.001 \\
\hline
\end{tabular}

95\% Cl - 95\% confidence interval; ACE-I - angiotensin-converting enzyme inhibitor; ASD - atrial septal defect; NS - not significant; PFO - patent foramen ovale; SF-36 - 36-item SF-36 questionnaire; RVD3 - longitudinal right ventricular dimension; TAPSE - tricuspid annular plane systolic excursion.

The results of percutaneous ASC closure are very promising, ${ }^{13}$ but the procedure is not free of potential complications. ${ }^{20-22}$ Percutaneous occlusion does not lead to postoperative scarring on the chest, which is a significant advantage from the patient's perspective. This may have a major impact on the QoL, especially that of young women. ${ }^{11}$ The assessment of health status after correction of the ASC is based primarily on the results of echocardiographic, radiological and laboratory studies. ${ }^{7}$ However, they do not always reflect a satisfactory level of QoL. In this study, it was shown that the QoL between patients before percutaneous occlusion of ASD and PFO differs. Special attention is drawn to a subjectively low grade in the assessment of RP (limitations in performing roles and/or in work ability), SF (social life, meetings with family) and RE (anxiety, bad mood, lack of work) subscales, but not the MH (nervousness, depression, unhappiness, and sadness) and VT (willingness to live, tiredness, lack of energy) subscales. On the other hand, in the self-assessment reflecting $\mathrm{GH}$, a trend towards lower QoL was observed in patients with ASD. After ASC occlusion, QoL in all subscales improved, except for sense of pain. Deterioration of patient functioning (performing roles) due to physical health (limitation in work ability) at the 6-month followup after ASD occlusion may result from restrictions recommended by doctors and suggestions by the patient's family members before the procedure. Such situations are very common and unfortunately are also transferred to the post-procedural period. ${ }^{11,12}$ Asymptomatic patients or those with mild symptoms (a majority of patients with PFO) may not experience such a significant improvement after the procedure when compared to patients with ASD, in whom effective occlusion of the defect is associated with resolution of significant ailments. Quality of life between patients with ASD and PFO before the procedure did not differ in the subscales of BP, MH, VT, and GH. The existence of comorbidities, such as arterial hypertension, episodes of AF, dyspnea and palpitations, as well as the use of medications (CCB, $\beta$-blockers, and ACE-I), influences QoL. Significant associations of change in SF-36 total score with a reduction of the abovementioned symptoms after ASC occlusion were noted. Patients after ASD and PFO occlusion did not differ in regard to SF, BP, MH, and VT. Similarly, after percutaneous ASD closure, Komar et al. ${ }^{4}$ observed a significant improvement in the clinical condition of patients and reduction in the frequency of dyspnea, palpitations and resolution of right heart volume overload. This was reflected by a decrease in right atrial area and right ventricular size (diastolic and systolic dimension as well as right ventricular area) and a significant improvement in QoL. On the other hand, Siudalska et al. ${ }^{11}$ observed decreased overall QoL and physical health in patients after surgical correction of ASD than in the control group. At the same time, there were no differences in mental health between the groups. The only category significantly differentiating the compared groups was social functioning, which was worse in patients who had undergone surgical correction of ASD. Somatic disorders were significantly more common in surgical patients. In our study, we have shown that the procedure-related change in self-assessed QoL by patients was associated with right ventricular and atrial dimensions. In patients with ASD, change in SF-36 total score was predicted by TAPSE and RVD3, while in patients with PFO, this change was predicted by TAPSE, lack of arterial hypertension and ACE-I use. Therefore, in both groups, patients with better right ventricular function (TAPSE) before percutaneous closure of ASC may benefit the most, in terms of QoL improvement, from ASC occlusion. In patients with ASD, increased longitudinal right ventricular dimension plays an important role, while in patients with PFO, lack of arterial hypertension and ACE-I use are important factors. These observations are in line with previous studies in different groups of patients. ${ }^{23,24}$

Our study has several limitations, including the observational character of the study, a relatively short follow-up and 
a small group of patients investigated. However, the changes described are significant. On the other hand, longer Holter ECG monitoring could increase detection and provide more detailed characteristics of arrhythmias.

\section{Conclusions}

Patients with atrial septal defect have a lower QoL than patients with patent foramen ovale, both before and after percutaneous ASC occlusion. Improvement of quality of life in patients with atrial septal defect is higher than in those with patent foramen ovale. The change in selfassessed QoL after the procedure was associated with episodic arrhythmia and predicted by echocardiographic and clinical parameters. Patient education on potential role limitations should be considered in patients with ASC, especially those with ASD.

\section{ORCID iDs}

Maria Lelakowska (10) https://orcid.org/0000-0003-4456-5954 Paweł Tomasz Matusik (1) https://orcid.org/0000-0001-5788-575X Piotr Stanisław Podolec (1) https://orcid.org/0000-0001-6101-2935 Maria Olszowska (1) https://orcid.org/0000-0003-3037-0400 Jadwiga Maria Nessler (1) https://orcid.org/0000-0002-5076-5816 Natalia Podolec (1) https://orcid.org/0000-0003-0192-7310 Tadeusz Przewłocki @i https://orcid.org/0000-0002-9575-7270 Monika Komar (10 https://orcid.org/0000-0001-5341-2947

\section{References}

1. Komar M, Podolec P, Przewłocki T, et al. Transoesophageal echocardiography can help distinguish between patients with "symptomatic" and "asymptomatic" patent foramen ovale. Kardiol Pol. 2012;70(12): 1258-1263.

2. Hari P, Pai RG, Varadarajan P. Echocardiographic evaluation of patent foramen ovale and atrial septal defect. Echocardiography. 2015; 32(Suppl 2):S110-124.

3. Sabiniewicz R. Interventional, percutaneous closure of interatrial communication: Atrial septal defect and patent foramen ovale. Ann Acad Med Gedan. 2012;62 (Suppl. 4):1-219.

4. Komar M, Przewłocki T, Olszowska M, Sobień B, Podolec P. The benefit of atrial septal defect closure in elderly patients. Clin Interv Aging. 2014;9:1101-1107.

5. Komar M, Przewłocki T, Olszowska M, Sobień B, Tomkiewicz-Pająk L, Podolec P. Is it worth closing the atrial septal defect in patients with insignificant shunt? Postepy Kardiol Interwencyjnej. 2014;10(2):78-83.

6. Komar M, Przewłocki T, Olszowska M, et al. Conduction abnormality and arrhythmia after transcatheter closure of atrial septal defect. Circ J. 2014;78(10):2415-2421.

7. Podolec P, Przewłocki T, Pieculewicz M, et al. Early haemodynamic changes after transcatheter closure of atrial septal defect [in Polish]. Przegl Lek. 2004;61(6):640-643.
8. Fang F, Luo XX, Lin QS, et al. Characterization of mid-term atrial geometrical and electrical remodeling following device closure of atrial septal defects in adults. Int J Cardiol. 2013;168(1):467-471.

9. Lelakowska-Pieła M, Pudło J, Rydlewska A, Senderek T, Lelakowski J. Quality of life in patients after anti-arrhythmic devices implantation [in Polish]. Pol Merkur Lekarski. 2013;35(210):331-338.

10. Liszniański P, Pudło J, Lelakowska-Pieła M, Nowak J, Lelakowski J. Analysis of RF ablation treatment on quality of life in patients with cardiac arrhythmias [in Polish]. Przegl Lek. 2015;72(1):1-5.

11. Siudalska H, Lipczyńska M, Leszczyńska $K$, et al. Quality of life in patients following atrial septal defect surgical repair. Folia Cardiol. 2004;11(8):599-606.

12. Cieślik $B$. Influence of the heart diseases on quality of life - literature review [in Polish]. Acta Bio-Opt InfMed Biomed Eng. 2014;20(2):101-118.

13. Lelakowska M, Komar M, Matusik PT, Nessler J, Podolec P, Olszowska M. Transcatheter closure of atrial septal communication: Impact on P-wave dispersion, duration and arrhythmia in mid-term follow-up. Kardiol Pol. 2018;76(10):1465-1473.

14. Warnes CA, Williams RG, Bashore TM, et al. ACC/AHA 2008 Guidelines for the Management of Adults with Congenital Heart Disease: a report of the American College of Cardiology/American Heart Association Task Force on Practice Guidelines (writing committee to develop guidelines on the management of adults with congenital heart disease). Circulation. 2008;118(23):714-833.

15. Rudski LG, Lai WW, Afilalo J, et al. Guidelines for the echocardiographic assessment of the right heart in adults: A report from the American Society of Echocardiography endorsed by the European Association of Echocardiography, a registered branch of the European Society of Cardiology, and the Canadian Society of Echocardiography. J Am Soc Echocardiogr. 2010;23(7):685-713.

16. Lang RM, Badano LP, Tsang W, et al; American Society of Echocardiography; European Association of Echocardiography. EAE/ASE recommendations for image acquisition and display using three-dimensional echocardiography. J Am Soc Echocardiogr. 2012;25(1):3-46.

17. Lang RM, Badano LP, Mor-Avi V, et al. Recommendations for cardiac chamber quantification by echocardiography in adults: An update from the American Society of Echocardiography and the European Association of Cardiovascular Imaging. J Am Soc Echocardiogr. 2015; 28(1):1-39.

18. Błażejewski J, Sinkiewicz W. Echocardiographic assessment of the right heart - 2015 expert guidelines in clinical practice. Folia Cardiol. 2017;12:171-178.

19. Pepi M, Evangelista A, Nihoyannopoulos P, et al; European Association of Echocardiography. Recommendations for echocardiography use in the diagnosis and management of cardiac sources of embolism: European Association of Echocardiography (EAE) (a registered branch of the ESC). Eur JEchocardiogr. 2010;11(6):461-476.

20. Gutiérrez-Barrios A, Lacal-Peña JM, Vignau-Cano JM, et al. Silent early migration of a Figulla ${ }^{\circledR}$ septal occluder into the left ventricle. Kardiol Pol. 2017;75(7):724.

21. Cottini M, Pergolini A, Musumeci F. Atrial septal defect occluder dislocation engaged through the tricuspid valve: Surgical removal via right thoracotomy. Kardiol Pol. 2017;75(3):279.

22. Goreczny S, Bedair R, Bilska K, Morgan G. Retrieving a large embolised atrial septal occluder - hooked... and landed. Kardiol Pol. 2017;75(3):277.

23. Wolfel EE. Effects of ACE inhibitor therapy on quality of life in patients with heart failure. Pharmacotherapy. 1998;18(6):1323-1334.

24. Trevisol DJ, Moreira LB, Kerkhoff A, Fuchs SC, Fuchs FD. Health-related quality of life and hypertension: A systematic review and metaanalysis of observational studies. J Hypertens. 2011;29(2):179-188. 